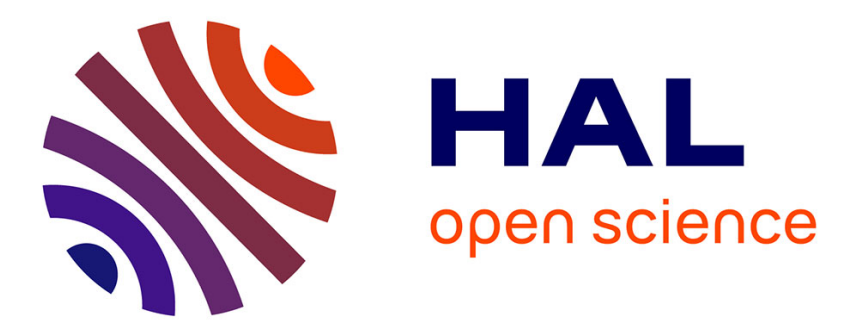

\title{
BDNF-TrkB signaling interacts with the GABAergic system to inhibit rhythmic swallowing in the rat
}

Bruno Bariohay, Catherine Tardivel, Juliette Pio, Andre Jean, Bernadette Felix

\section{- To cite this version:}

Bruno Bariohay, Catherine Tardivel, Juliette Pio, Andre Jean, Bernadette Felix. BDNFTrkB signaling interacts with the GABAergic system to inhibit rhythmic swallowing in the rat. AJP - Regulatory, Integrative and Comparative Physiology, 2008, 295 (4), pp.R1050-R1059. 10.1152/ajpregu.90407.2008 . hal-02660599

\section{HAL Id: hal-02660599 \\ https: / hal.inrae.fr/hal-02660599}

Submitted on 30 May 2020

HAL is a multi-disciplinary open access archive for the deposit and dissemination of scientific research documents, whether they are published or not. The documents may come from teaching and research institutions in France or abroad, or from public or private research centers.
L'archive ouverte pluridisciplinaire HAL, est destinée au dépôt et à la diffusion de documents scientifiques de niveau recherche, publiés ou non, émanant des établissements d'enseignement et de recherche français ou étrangers, des laboratoires publics ou privés. 


\section{Bruno Bariohay, Catherine Tardivel, Juliette Pio, André Jean and Bernadette}

Félix

Am J Physiol Regulatory Integrative Comp Physiol 295:1050-1059, 2008. First published Aug 6, 2008; doi:10.1152/ajpregu.90407.2008

You might find this additional information useful...

This article cites 45 articles, 20 of which you can access free at:

http://ajpregu.physiology.org/cgi/content/full/295/4/R1050\#BIBL

This article has been cited by 1 other HighWire hosted article:

A tasty morsel: the role of the dorsal vagal complex in the regulation of food intake and swallowing. Focus on "BDNF/TrkB signaling interacts with GABAergic system to inhibit rhythmic swallowing in the rat," by Bariohay et al.

E. F. Bailey

Am J Physiol Regulatory Integrative Comp Physiol, October 1, 2008; 295 (4): R1048-R1049.

[Full Text] [PDF]

Updated information and services including high-resolution figures, can be found at:

http://ajpregu.physiology.org/cgi/content/full/295/4/R1050

Additional material and information about American Journal of Physiology - Regulatory, Integrative and Comparative Physiology can be found at:

http://www.the-aps.org/publications/ajpregu

This information is current as of September 7, 2010 .

The American Journal of Physiology - Regulatory, Integrative and Comparative Physiology publishes original investigations that illuminate normal or abnormal regulation and integration of physiological mechanisms at all levels of biological organization, ranging from molecules to humans, including clinical investigations. It is published 12 times a year (monthly) by the American

Physiological Society, 9650 Rockville Pike, Bethesda MD 20814-3991. Copyright @ 2008 by the American Physiological Society. ISSN: 0363-6119, ESSN: 1522-1490. Visit our website at http://www.the-aps.org/. 


\title{
BDNF-TrkB signaling interacts with the GABAergic system to inhibit
}

\section{rhythmic swallowing in the rat}

\author{
Bruno Bariohay, Catherine Tardivel, Juliette Pio, André Jean, and Bernadette Félix \\ Centre de Recherche en Neurobiologie-Neurophysiologie de Marseille, CRN2M, Université de la Méditerranée, Université \\ Paul Cézanne, Centre National de la Recherche Scientifique Unité Mixte de Recherche 6231, USC-Institut National de la \\ Recherche Agronomique 2027, Département de Physiologie NeuroVégétative, Campus de St Jérôme, Marseille, France
}

Submitted 7 May 2008; accepted in final form 5 August 2008

\begin{abstract}
Bariohay B, Tardivel C, Pio J, Jean A, Félix B. BDNF-TrkB signaling interacts with the GABAergic system to inhibit rhythmic swallowing in the rat. Am J Physiol Regul Integr Comp Physiol 295: R1050-R1059, 2008. First published August 6, 2008; doi:10.1152/ajpregu.90407.2008.— Brain-derived neurotrophic factor (BDNF) acts as an anorexigenic factor in the dorsal vagal complex (DVC) of the adult rat brain stem. The DVC contains the premotoneurons controlling swallowing, a motor component of feeding behavior. Although rats with transected midbrain do not seek out food, they are able to swallow and to ingest food. Because BDNF and tropomyosin-related kinase B (TrkB) receptors are expressed in the DVC, this study hypothesized that BDNF could modify the activity of premotoneurons involved in swallowing. Repetitive electrical stimulation of the superior laryngeal nerve (SLN) induces rhythmic swallowing that can be recorded with electromyographic electrodes inserted in sublingual muscles. We show that a microinjection of BDNF in the swallowing network induced a rapid, transient, and dose-dependant inhibition of rhythmic swallowing. This BDNF effect appeared to be mediated via TrkB activation, since it no longer occurred when TrkB receptors were antagonized by K-252a. Interestingly, swallowing was inhibited when subthreshold doses of BDNF and GABA were coinjected, suggesting a synergistic interaction between these two signaling substances. Moreover, BDNF no longer had an inhibitory effect on swallowing when coinjected with bicuculline, a $\mathrm{GABA}_{\mathrm{A}}$ receptor antagonist. This blockade of BDNF inhibitory effect on swallowing was reversible, since it reappeared when BDNF was injected 15 min after bicuculline. Finally, we show that stimulation of SLN induced a decrease in BDNF protein within the DVC. Together, our results strongly suggest that BDNF inhibits swallowing via modulation of the GABAergic signaling within the central pattern generator of swallowing.
\end{abstract}

brain-derived neurotrophic factor; $\gamma$-aminobutyric acid; medullary solitary tract nucleus; dorsal vagal complex; feeding behavior

INCREASING ATTENTION is being focused on various neuropeptides for their ability to regulate functions related to food intake. Among these, the brain-derived neurotrophic factor (BDNF), a member of the neurotrophin family, has recently attracted attention because it is involved in the central regulation of food intake, acting as an anorexigenic factor in the adult rodent. Indeed, infusion of BDNF in the lateral ventricles induces a decrease in food intake and weight loss in rats (32). Moreover, mice heterozygous for targeted disruption of BDNF, as well as conditional BDNF mutants, show hyperphagia and obesity $(21,36)$. BDNF is abundantly expressed in the adult

Address for reprint requests and other correspondence: B. Félix, Centre de Recherche en Neurobiologie-Neurophysiologie de Marseille, CRN2M, Université de la Méditerranée, Université Paul Cézanne, CNRS UMR 6231, USC-INRA 2027, Département de Physiologie NeuroVégétative, Campus de St Jérôme, Ave. Escadrille Normandie Niémen, 13397 Marseille cedex 20, France (e-mail: bernadette.felix@univ-cezanne.fr). brain, and more especially in the hypothalamus and caudal brain stem (4), which are both important structures for maintaining normal weight and play major roles in the regulation of energy homeostasis. However, most studies so far have mainly focused on the hypothalamus. Xu et al. (44) demonstrated that BDNF expression in the ventromedial hypothalamic nucleus $(\mathrm{VMH})$ is regulated by nutritional state. In addition, Wang et al. (40-42) showed that BDNF injections within the VMH or the paraventricular nucleus of the hypothalamus induce a decrease in food intake and body weight. Focusing on the brain stem, we recently showed that BDNF also exerts its anorexigenic effects within the dorsal vagal complex (DVC). Indeed, infusion of exogenous BDNF within the DVC induces anorexia and weight loss. Moreover, in the DVC the BDNF protein content is modulated by nutritional state and increased by anorexigenic hormones cholecystokinin (CCK) and leptin (2). Although BDNF protein can bind to two structurally unrelated plasma membrane receptors (31), the low-affinity p75 receptor and the high-affinity tropomyosin-related kinase type B (TrkB) receptor, only the latter has been shown to be involved in BDNF anorexigenic effects at the central level. Mice with overall reduced expression of TrkB show hyperphagia and excessive body weight (44). In the hypothalamus, the feeding inhibition induced by BDNF injection within the $\mathrm{VMH}$ was attenuated by pretreatment with a TrkB-Fc fusion protein that blocks binding of BDNF with TrkB (42). In the DVC, TrkB receptors are highly expressed (45); however, their involvement in anorexigenic BDNF effects remains to be determined.

The DVC, located dorsally in the caudal brain stem, comprises the area postrema (AP), the nucleus tractus solitarii (NTS) and the dorsal motor nucleus of the vagus nerve (DMNX). The DVC is an integrative brain stem center for autonomic functions, for example, integrating satiety signals so as to adjust meal size as a function of fat stores (25). However, the role of the DVC in food intake control is not limited to the integration of peripheral signals; it is also involved in the programming of the motor component of feeding behavior. Thus rats with fully transected midbrain do not seek out food but are able to ingest food applied in the mouth and to terminate a meal by ceasing to ingest as shown by food dribbling from the mouth. Moreover, these rats are able to adapt their meal size as a function of the energy content of food (12-14). In addition, it has been clearly established that the DVC contains the neural network that forms the central pattern generator of swallowing (SwCPG). It has been shown that

\footnotetext{
The costs of publication of this article were defrayed in part by the payment of page charges. The article must therefore be hereby marked "advertisement" in accordance with 18 U.S.C. Section 1734 solely to indicate this fact.
} 
sensory afferent fibers traveling through the superior laryngeal nerve (SLN), a branch of the vagus nerve that plays an important role in triggering swallowing, contact premotoneurons. These premotoneurons are located within the interstitial and intermediate subnuclei of the NTS that constitute the so-called "swallowing center" or SwCPG (19). Interestingly, it was shown recently that local application of the anorexigenic hormone leptin within the NTS can modulate the act of swallowing (9), which is a fundamental motor activity that constitutes the last step of ingestive behavior (19).

Since 1) BDNF is highly expressed in the DVC, where it plays a role as an anorexigenic factor, 2) the SwCPG is mainly located in the DVC, 3) leptin microinjection in the DVC inhibits swallowing, and 4) leptin modulates BDNF protein content within the DVC, we hypothesized that BDNF may also modulate the swallowing reflex in the rat.

$\gamma$-Aminobutyric acid (GABA), a well-known neurotransmitter in the brain, is also known to induce a rapid, transient, and dose-dependent inhibition of rhythmic swallowing when injected within the NTS $(9,43)$. In fact, in physiological conditions swallowing appears to be subject to a tonic GABAergic inhibition (43). Interestingly, various data have shown that BDNF affects GABAergic signaling within the brain $(20,28$, $29,33)$.

In consequence, the present study was performed to 1 ) evaluate the actions of BDNF and TrkB receptors on swallowing, 2) determine whether GABA can mediate putative BDNF effects on swallowing, and 3) determine whether the endogenous BDNF protein content in the DVC is sensitive to the SLN stimulation paradigm used to induce swallowing.

\section{METHODS}

The experimental procedures described here were carried out in accordance with European guidelines for the care and use of laboratory animals (Council Directive 86/6009/EEC) and the French law on the Protection of Animals (1987; revised 2001) and under a license granted to A. Jean (Préfecture des Bouches du Rhône authorization no. 13-78).

Surgical procedures. Experiments were performed on 44 adult male Wistar rats, weighing 250-350 g (Charles River, l'Arbresle, France), anesthetized with a mixture of ketamine $(100 \mathrm{mg} / \mathrm{ml})$ and xylazine $(15 \mathrm{mg} / \mathrm{ml}$; Centravet, Dinan, France) in a proportion of $90 \%$ and $10 \%$, respectively. Anesthesia was then continued by perfusion of the same mixture through a catheter inserted in the peritoneal cavity, at a rate of $0.5-1 \mathrm{ml} / \mathrm{h}$. The SLN was dissected free from surrounding tissues and placed on miniature bipolar electrodes. The head of the animal was then fixed in a stereotaxic frame (Horsley and Clarke apparatus adapted for rats) in such a position that, after occipitoparietal craniotomy and removal of the posterior part of the cerebellum, the floor of the fourth ventricle appeared to lie in a horizontal plane. The surface of the medulla was exposed in order to allow the stereotaxic introduction of the microelectrode in the vicinity of the NTS and was covered with warm liquid paraffin.

Stimulations, recordings, and signal analysis. Swallowing was triggered by peripheral stimulation of the sensitive fibers contained in the SLN. Stimulation with a long train of pulses produced several swallows [or rhythmic swallowing recorded by electromyography (EMG)] at a rhythm depending on stimulation frequency. In the present study, repetitive long trains of pulses (5-s duration at 5- to $30-\mathrm{Hz}$ frequency every $30 \mathrm{~s}$ ) were used. The pulse voltage, duration, and frequency varied according to the animal (1.5-5 V; 0.02-0.5 ms) in such a way as to trigger four to six rhythmic swallows. To monitor swallowing, the EMG activity of sublingual muscles (mainly the geniohyoid) was recorded by means of bipolar copper wire electrodes inserted into the muscles with a hypodermic needle. An electrocardiogram (ECG) picked up by subcutaneous electrodes on each side of the thorax and respiratory activity recorded by a mechanotransducer placed around the thorax were monitored. Moreover, the ECG and swallowing EMG signals were fed to loud speakers for auditory monitoring. Rectal temperature was monitored and maintained around $37^{\circ} \mathrm{C}$ with a heating pad. The EMG, ECG, and respiration signals were recorded on a computer with an analog-to-digital interface (PowerLab 8SP data acquisition with Chart5.5 software for Windows, ADInstruments). EMG activity triggered by the 5-s SLN stimulation was analyzed with a specially designed computer program. This analysis allowed us to determine 1) the number of swallows triggered by SLN stimulation and 2) the mean area under the envelope of EMG signals (obtained by an average of 8 -ms buffers smoothed by using a low-pass filter ; time constant $=24 \mathrm{~ms}$ ) recorded during SLN stimulation. This last value, expressed in arbitrary units, gives a good representation of swallowing intensity. Cardiac and respiratory frequencies were analyzed continuously during the experiment. All calculated values were normalized as percentages of those generated from control values.

Microinjections. Pressure ejections of drug solutions were performed through glass pipettes (70- $\mu \mathrm{m}$ OD at the tip) with an injection device (PMI-200, Dagan, Minneapolis, MN). The pressure ejection was adjusted between 150 and $200 \mathrm{kPa}$ for pulses of 3-5 s in duration, and the injected volume was 50-100 nl. The following substances, obtained from Sigma (Saint Quentin Fallavier, France), were used: $\operatorname{BDNF}(7.2,36$, or $72 \mathrm{fmol})$, bicuculline (250 or $500 \mathrm{pmol})$, and GABA (0.1 fmol, $0.1 \mathrm{pmol}$, or $0.1 \mathrm{nmol})$. All of these drugs were dissolved in $\mathrm{NaCl} 0.9 \%$ solution. K-252a (25 fmol) obtained from Calbiochem (VWR International, SAS) was first dissolved in $100 \%$ dimethyl sulfoxide (DMSO) and then in $\mathrm{NaCl} 0.9 \%$.

Histological controls. In 15 experiments, pontamine blue (4\%) was added to the drug solution injected. It had previously been ascertained that this dye alone produces no effect on swallowing. At the end of these experiments, the brain stem was removed and placed in a solution of $4 \%$ formaldehyde. Frontal frozen sections (50 $\mu \mathrm{m}$ thick) were cut and examined for histological localization of the injection site.

Experimental procedures. We studied how various drugs [BDNF,

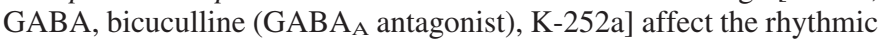
swallowing elicited by repetitive stimulations of the SLN. Previous studies have shown that a microinjection of glutamate within the intermediate NTS, containing the SwCPG, can initiate swallowing (9, $22,23)$. Thus glutamate microinjections (1 fmol) were used as a control to check that microelectrodes were positioned within the SwCPG. When such a glutamate microinjection elicited swallowing, the stereotaxic coordinates were conserved for BDNF, GABA, bicuculline, and/or K-252a injections. The precise coordinates extended between 0.5 and $0.7 \mathrm{~mm}$ rostral to the caudal edge of the AP (taken as 0 ), $0.6-0.8 \mathrm{~mm}$ laterally, and $0.4-0.8 \mathrm{~mm}$ in depth, roughly corresponding to those previously used (9). The stimulation was applied to the ipsilateral SLN to test the effects of various drugs on swallowing and was applied to both SLNs to test the effect of SLN stimulation on endogenous BDNF protein content at the DVC and hypothalamus levels. A control sequence involving three trains of stimulations of $90 \mathrm{~s}$ was performed before drug injection. The mean values obtained during this sequence were used as control values. Afterwards, stimulations and recordings were maintained until recovery.

DVC and hypothalamus dissection. Endogenous BDNF protein content was measured in the DVC and, for comparison, in the hypothalamus of the same rats after SLN bilateral stimulation (performed from 2:00 PM to 4:00 PM for each rat, $n=5$ ). Control animals $(n=5)$ were operated on at the same time, but no stimulation was applied. After $2 \mathrm{~h}$ the rats were decapitated. Each brain was removed rapidly from the skull and split by a transverse cut between 
cerebral hemispheres and cerebellum. The hypothalamus was dissected from the forebrain under binocular control (Nikon SMZ-2B; Fabre Mesurelec). The brain stem-upper cervical spinal cord block was placed on a tissue chopper (McIlwain Tissue chopper, Mickle Laboratory Engineering) and serially sectioned into $500-\mu \mathrm{m}$-thick slices. DVC was microdissected from three relevant slices under binocular control in ice-cold saline. Tissue samples (DVC and hypothalamus) were immediately placed in microcentrifuge tubes, frozen in liquid nitrogen, and stored at $-80^{\circ} \mathrm{C}$ until use. For each rat, the total amount of time from death to sample freezing was under $10 \mathrm{~min}$. To rule out interference from the known circadian variation in BDNF expression (34), two rats (1 stimulated vs. 1 nonstimulated) were processed simultaneously every day for 5 days.

Protein extraction and dosage. Tissue samples were homogenized in lysis buffer (100 $\mu \mathrm{l}$ for DVC, $500 \mu \mathrm{l}$ for hypothalamus) [in $\mathrm{mM}$ : $137 \mathrm{NaCl}, 20$ Tris $\cdot \mathrm{HCl}, 1$ sodium orthovanadate, and 1 phenylmethylsulfonyl fluoride, with $1 \%$ Triton X-100, 10\% glycerol, and protease inhibitor cocktail (Sigma)], incubated $30 \mathrm{~min}$ at $4^{\circ} \mathrm{C}$, and centrifuged at $10000 \mathrm{~g}\left(30 \mathrm{~min}\right.$ at $\left.4^{\circ} \mathrm{C}\right)$. The supernatants were collected, and protein concentration was determined with the BCA Protein Assay Kit (Novagen, Darmstadt, Germany) according to the manufacturer's instructions.

BDNF immunoassay. BDNF protein content was determined with a commercially available enzyme-linked immunosorbent assay (ELISA) kit (Promega, Charbonnière, France) according to the manufacturer's instructions. The detection limit of the assay is $15 \mathrm{pg} / \mathrm{ml}$, and the cross-reactivity with other related neurotrophic factors is $<3 \%$. For each sample, $30 \mu \mathrm{g}$ of total proteins was used to determine BDNF content. The within-assay variability was $<3 \%$, and all relevant comparisons were made within the same assay. BDNF concentration was determined as picograms per milligram of total protein, and relative changes in BDNF content between nervous structures of stimulated rats were expressed as percentage of sham treatment values.

Statistical analyses. Statistical analyses were performed with analysis of variance (2-way ANOVA) followed by Fisher's protected least significant difference test (StatView for Windows 5.0.1; SAS Institute). Data are expressed as means \pm SE. Differences were considered significant when $P<0.05$.

\section{RESULTS}

Peripheral afferent stimulation triggered reflex swallowing. Repetitive electrical stimulation of the SLN branch of the vagus $(2.5 \mathrm{~V}, 0.6 \mathrm{~ms}, 20 \mathrm{~Hz}, 5 \mathrm{~s}$ every $30 \mathrm{~s})$ elicited rhythmic swallowing (Fig. 1A). The number $(4.87 \pm 0.08 ; n=81)$ and the mean intensity $(102.44 \pm 9.41$ arbitrary units $)$ of swallows triggered by SLN stimulation were stable throughout the experiment. At the same time as this rhythmic swallowing, there was a total cessation of respiration.

$B D N F$ microinjections within the SwCPG inhibited swallowing. The present results, obtained from 36 trials performed on 15 rats, show that BDNF microinjections in the SwCPG induced a significant dose-dependent decrease in number $\left(\mathrm{F}_{3}\right.$ : 44.98, $P<0.0001$; Fig. $1 B$ and Fig. $2 A 1)$ and mean intensity $\left(\mathrm{F}_{3}=40.37, P<0.0001\right.$; Fig. $\left.2 A 2\right)$ of swallows recorded during SLN stimulation. At 36 fmol (11 trials, 4 rats) and 72 fmol (10 trials, 5 rats) of BDNF, these effects occurred during the stimulating pulse immediately following BDNF microinjection (Figs. $1 B$ and $2 A$ ). Considering that stimulations were repeated every $30 \mathrm{~s}$, it can be deduced that the latency of these BDNF inhibitory effects was $<30 \mathrm{~s}$. The BDNF inhibitory effects were transient, with a significant decrease in the number and mean intensity of swallows until $240 \mathrm{~s}$ for $72 \mathrm{fmol}$ of BDNF. The decrease was maximal $60 \mathrm{~s}$ after BDNF microin-
$\mathbf{A}$
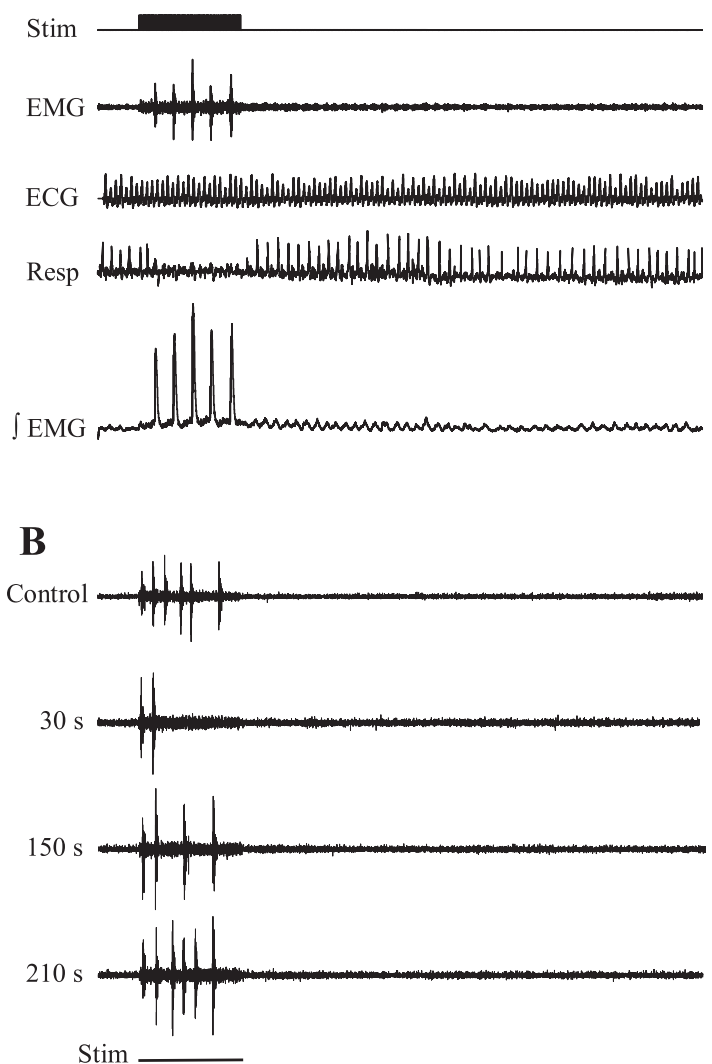

Fig. 1. Polygraphic recordings during the experiment. A: representative view of parameters recorded in the rat. Stim, stimulation of the superior laryngeal nerve (SLN) at 20 pulses/s during $5 \mathrm{~s}$ (pulse parameters $1.5 \mathrm{~V}$ and $0.2 \mathrm{~ms}$ ); EMG, electromyogram from sublingual muscles (note rhythmic swallowing triggered by SLN stimulation); ECG, electrocardiogram; Resp, respiration (note respiration blockade during SLN stimulation triggering rhythmic swallowing); (EMG, electromyogram envelope signal normalized. $B$ : brain-derived neurotrophic factor (BDNF) microinjection $(36 \mathrm{fmol})$ within the medullary nucleus tractus solitarii (NTS) inhibited rhythmic swallowing triggered by SLN stimulation. Note that the inhibition of rhythmic swallowing was rapid (30 s after BDNF injection) and transient (recovery after $210 \mathrm{~s}$ ). Stimulation parameters were $3 \mathrm{~V}, 1.5 \mathrm{~ms}, 25 \mathrm{~Hz}$ during $5 \mathrm{~s}$.

jection, reaching $55 \%$ for the number of swallows $(P<$ $0.0001)$ and $60 \%$ for the mean intensity $(P<0.0001)$. In comparison, at 36 fmol of BDNF inhibitory effects were shorter (210 s for the number of swallows and $180 \mathrm{~s}$ for the mean intensity of swallows) and less powerful, with a maximal $30 \%$ decrease in the number of swallows observed $90 \mathrm{~s}$ after BDNF microinjection $(P<0.05)$ and a maximal $28 \%$ decrease in the mean intensity of swallows observed $30 \mathrm{~s}$ after injection $(P<0.05)$. In contrast, BDNF at 7.2 fmol (15 trials, 4 rats $)$ failed to significantly alter the number and intensity of swallows; therefore this BDNF dose could be considered as subthreshold under our experimental conditions.

Since the BDNF inhibitory effect was rapid, transient, and maximal during the first $90 \mathrm{~s}$ after BDNF microinjection, we quantified the mean number and intensity of swallows during this time course, corresponding to the first three SLN stimulations after BDNF microinjection. These results were compared with the three respective control sequences recorded before BDNF microinjection, and numerical values are summarized in Table 1. At 72 fmol of BDNF, reductions in the 90-s mean 

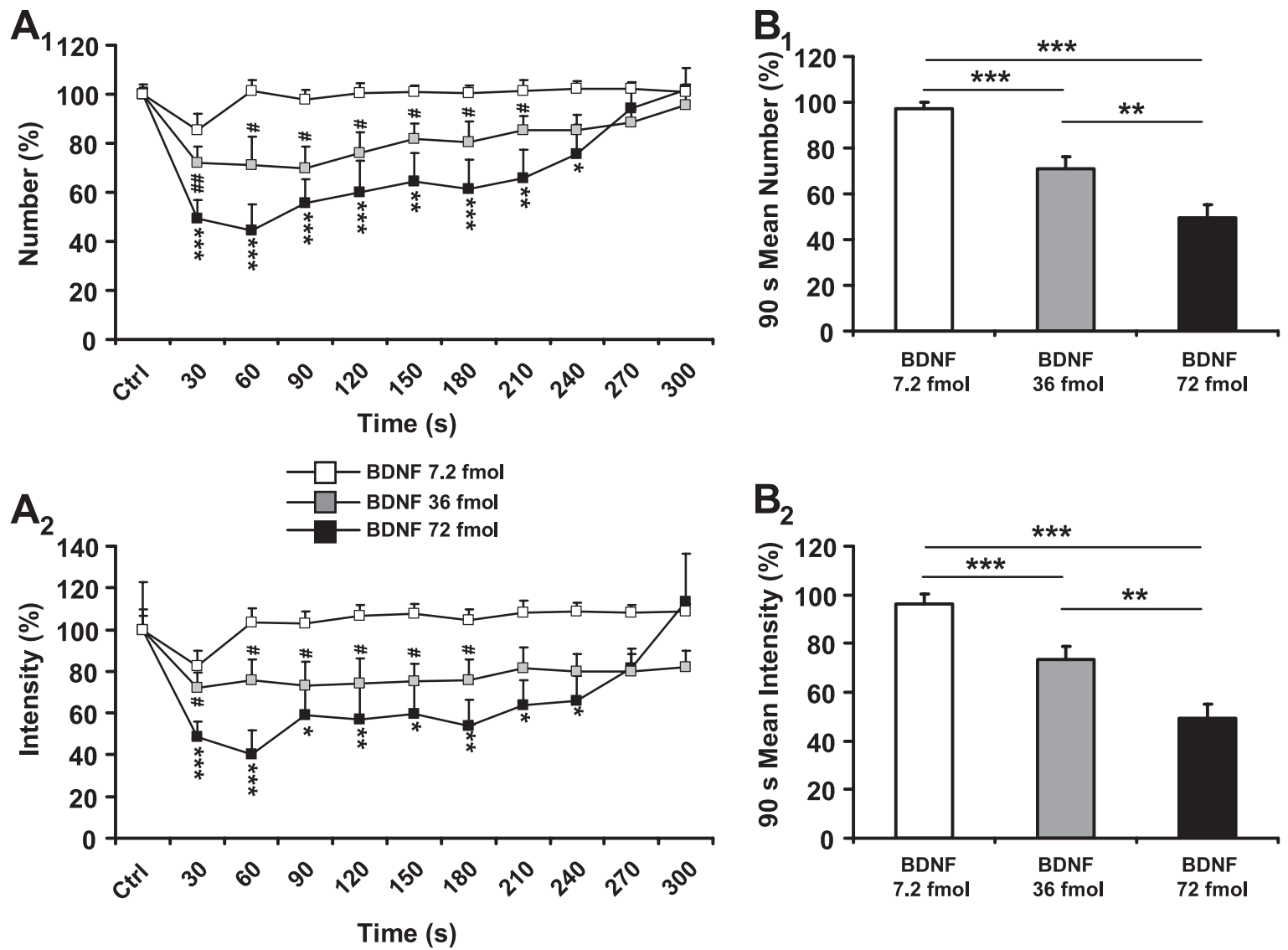

Fig. 2. BDNF microinjections within the central pattern generator of swallowing (SwCPG) inhibited rhythmic swallowing triggered by SLN stimulation. A: time course of the effects of various doses $(7.2 \mathrm{fmol}, n=15 ; 36 \mathrm{fmol}, n=11 ; 72 \mathrm{fmol}, n=10)$ of BDNF microinjections within the medullary NTS on the number (A1) and mean intensity (A2) of swallows triggered by SLN stimulation. Note time course variations according to the doses. Data represent the time after BDNF microinjection and until recovery. $B$ : graphic representation of the 90 -s maximal-intensity dose-dependent BDNF-induced inhibition of swallowing. Note that the 90-s mean number $(B 1)$ and intensity $(B 2)$ of swallows significantly decreased with increasing doses. Values are means \pm SE normalized to the respective responses recorded before BDNF microinjection $(\mathrm{Ctrl})$. \#P $<0.05$; \#\#P<0.001*P<0.05, **P<0.001, $* * * P<0.0001$.

number and intensity reached $50 \%(P<0.001$ and $P<0.05$, respectively) compared with control (Fig. $2 B$ and Table 1). At $36 \mathrm{fmol}$ of BDNF, reductions in the 90-s mean number and intensity reached $30 \%(P<0.001$, Fig. $2 B 1)$ and $27 \%(P<$ 0.01 , Fig. $2 B 2$ ), respectively, compared with control (Table 1).

BDNF at $72 \mathrm{fmol}$ inhibited the number and intensity of swallows, but without inducing any variation in cardiac frequency $(100 \pm 6.70 \%$ for control vs. $105.91 \pm 1.79 \%$ after BDNF injection, $P>0.05, n=10$; data not shown) or in respiratory frequency $(100 \pm 7.97 \%$ for control vs. $101.61 \pm$ $3.96 \%$ after BDNF injection, $P>0.05, n=10$; data not shown).
Blockade of TrkB receptors impaired the inhibitory effect of $B D N F$ on swallowing. When BDNF (36 fmol) was coinjected with $\mathrm{K}-252 \mathrm{a}(25 \mathrm{fmol})$, it no longer reduced the number $(P>$ $0.05, n=14$; Fig. $3 A)$ or the intensity $(P>0.05, n=14$; Fig. $3 B$ ) of swallows recorded during SLN stimulation. It is worth noting that injection of TrkB receptor inhibitor K-252a by itself had no effect on the number $(P>0.05, n=13$; Fig. $3 A)$ or the intensity $(P>0.05, n=13$; Fig. $3 B)$ of swallows triggered by SLN stimulation.

Inhibition of swallowing: interaction between BDNF and GABAergic signaling. To define the threshold level of GABA inhibiting swallowing, various doses were applied: $0.1 \mathrm{fmol}$,

Table 1. Changes in number and intensity of swallows triggered by SLN stimulation recorded during first $90 s$ after BDNF injections at different doses

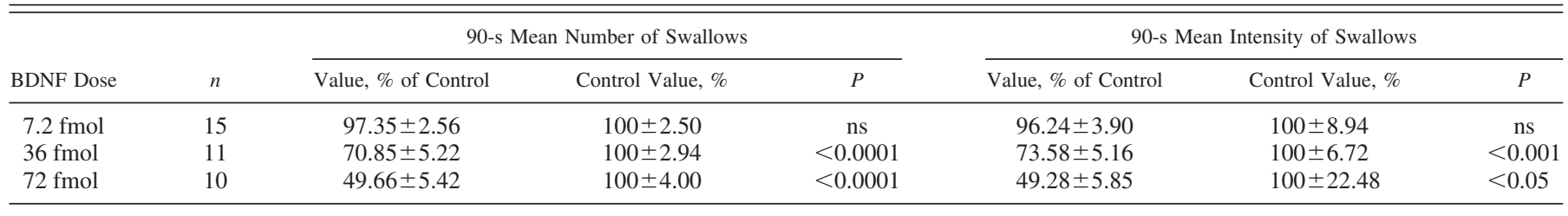

Values are means \pm SE normalized to the respective responses recorded $90 \mathrm{~s}$ before brain-derived neurotrophic factor (BDNF) injection. SLN, superior laryngeal nerve; ns, nonsignificant. 

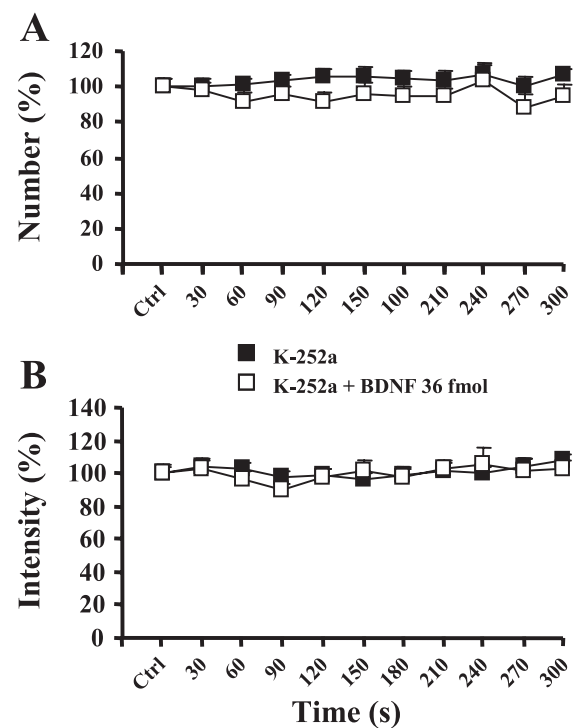

Fig. 3. Involvement of tropomyosin-related kinase B (TrkB) receptor in BDNF-induced swallowing inhibition. Time course of K-252a injections (25 fmol; $n=13$ ) compared with K-252a (25 fmol) and BDNF (36 fmol) coinjections $(n=14)$ within the SwCPG on the number $(A)$ and intensity $(B)$ of swallows elicited by SLN stimulation is shown. Note that no modification was recorded. Values are means \pm SE normalized to the respective responses recorded before injection $(\mathrm{Ctrl})$.

$0.1 \mathrm{pmol}$, and $0.1 \mathrm{nmol}$. As previously shown, a marked inhibition was obtained with $0.1 \mathrm{nmol}$ of GABA (9), while no effect was recorded with $0.1 \mathrm{fmol}$ of GABA (data not shown). ANOVA analysis revealed that $0.1 \mathrm{pmol}$ of GABA also failed to induce a significant inhibitory effect on the number (Fig. 4Al; $\mathrm{F}_{5}=0.445, P>0.05, n=10$ ) and intensity (Fig. 4A2; $\left.\mathrm{F}_{5}=1.396, P>0.05\right)$ of swallows recorded during the repetitive SLN stimulation. Thus we considered that $0.1 \mathrm{pmol}$ of GABA was the subthreshold dose to induce an inhibition of swallowing under our experimental conditions. However, at effective doses, both GABA and BDNF inhibited rhythmic swallowing. To evaluate a putative interaction of these compounds in their inhibitory effects, GABA and BDNF were coinjected at subthreshold doses, ineffective in significantly inhibiting swallowing by themselves (i.e., $0.1 \mathrm{pmol}$ GABA and 7.2 fmol BDNF). As can be seen in Fig. 4, Al and A2, such BDNF and GABA coinjections induced a significant decrease in the number (Fig. $4 A 1 ; \mathrm{F}_{5}=2.698, P<0.05, n=11$ ) and intensity (Fig. $4 A 2 ; \mathrm{F}_{5}=2.663, P<0.05$ ) of swallows, indicating a synergistic effect of the two substances.

In the same manner as for BDNF inhibitory effects, we quantified the mean number and intensity of swallows during the first $90 \mathrm{~s}$ after microinjections. The results obtained were compared with the three respective control sequences recorded before each microinjection (Fig. 4B), and numerical values are summarized in Table 2. Clearly, the 90-s mean number and intensity were altered neither for $0.1 \mathrm{pmol}$ of GABA $(P>$ $0.05)$ nor for $7.2 \mathrm{fmol}$ of BDNF $(P>0.05)$. However, when coinjected, $7.2 \mathrm{fmol}$ of BDNF and 0.1 pmol of GABA led to a significant decrease in the 90 -s mean number $(21 \%, P<0.001$; Fig. $4 B 1)$ and intensity (25\%, $P<0.05$; Fig. 4B2) of swallows.

Blockade of BDNF inhibitory effect on swallowing by a $G A B A_{A}$ antagonist. To further evaluate the involvement of GABAergic signaling in BDNF inhibitory effects on rhythmic swallowing induced by repetitive SLN stimulation, we first coinjected bicuculline (250 or $500 \mathrm{pmol})$, a $\mathrm{GABA}_{\mathrm{A}}$ receptor antagonist, with BDNF at effective dose $(36 \mathrm{fmol})$. As seen in Fig. $2 B$ and Table 2, 36 fmol of BDNF alone induced a significant decrease in the 90-s mean number and intensity of swallows. Bicuculline at $250 \mathrm{pmol}$ did not alter the swallowing reflex at 90 s: neither the mean number $(P>0.05, n=8$; Fig. 5A, Table 2$)$ nor the mean intensity $(P>0.05, n=8$; Fig. $5 B$,
Fig. 4. Synergistic interaction between BDNF and $\gamma$-aminobutyric acid (GABA) to inhibit rhythmic swallowing. A: time course of the effects of injections of BDNF (7.2 fmol, $n=15)$ and GABA (0.1 nmol, $n=10)$ alone compared with coinjections of 7.2 fmol BDNF and 0.1 nmol GABA $(n=11)$ within the SwCPG on the number $(A 1)$ and intensity $(A 2)$ of swallows. $B$ : graphic representation of the number $(B I)$ and intensity (B2) of swallows triggered by SLN stimulation during the first $90 \mathrm{~s}$ after injections of BDNF (7.2 fmol, $n=15)$ and GABA (0.1 nmol, $n=10)$ alone and coinjections of 7.2 fmol BDNF and 0.1 nmol GABA $(n=11)$. Note that BDNF and GABA alone did not change the swallowing parameters, while coinjection elicited a significant decrease in the number $(A 1$ and $B 1)$ and intensity $(A 2$ and $B 2$ ) of swallows. Values are means $\pm \mathrm{SE}$ normalized to the respective responses recorded just before injection. ${ }^{*} P<0.05$, $* * P<0.001, * * * P<0.0001$. ns, Nonsignificant.

Table 2. Changes in number and intensity of swallows triggered by SLN stimulation recorded during first $90 \mathrm{~s}$ after injections of various drugs

\begin{tabular}{|c|c|c|c|c|c|c|c|}
\hline \multirow[b]{2}{*}{ Drug Microinjection } & \multirow[b]{2}{*}{$n$} & \multicolumn{3}{|c|}{ 90-s Mean Number of Swallows } & \multicolumn{3}{|c|}{ 90-s Mean Intensity of Swallows } \\
\hline & & Value, $\%$ of Control & Control Value, $\%$ & $P$ & Value, $\%$ of Control & Control Value, $\%$ & $P$ \\
\hline BDNF $7.2 \mathrm{fmol}$ & 15 & $97.35 \pm 2.56$ & $100 \pm 2.50$ & ns & $96.24 \pm 3.90$ & $100 \pm 8.94$ & ns \\
\hline GABA $0.1 \mathrm{nmol}$ & 10 & $94.30 \pm 3.44$ & $100 \pm 2.33$ & ns & $95.36 \pm 6.81$ & $100 \pm 8.66$ & ns \\
\hline GABA $0.1 \mathrm{nmol}+$ BDNF $7.2 \mathrm{fmol}$ & 11 & $79.45 \pm 4.18$ & $100 \pm 5.60$ & $<0.001$ & $75.19 \pm 4.96$ & $100 \pm 10.80$ & $<0.05$ \\
\hline BDNF $36 \mathrm{fmol}$ & 11 & $70.85 \pm 5.22$ & $100 \pm 2.94$ & $<0.0001$ & $73.58 \pm 5.16$ & $100 \pm 6.72$ & $<0.001$ \\
\hline Bicu 250 pmol & 8 & $99.28 \pm 2.33$ & $100 \pm 4.59$ & ns & $103.40 \pm 3.90$ & $100 \pm 1.25$ & $\mathrm{~ns}$ \\
\hline Bicu $250 \mathrm{pmol}+\mathrm{BDNF} 36 \mathrm{fmol}$ & 15 & $95.60 \pm 3.99$ & $100 \pm 3.16$ & ns & $97.42 \pm 2.19$ & $100 \pm 5.41$ & ns \\
\hline Bicu 500 pmol & 11 & $160.16 \pm 13.09$ & $100 \pm 9.76$ & $<0.001$ & $184.32 \pm 16.97$ & $100 \pm 11.21$ & $<0.001$ \\
\hline Bicu 500 pmol + BDNF 36 fmol & 12 & $148.241 \pm 11.06$ & $100 \pm 10.52$ & $<0.05$ & $160.70 \pm 14.60$ & $100 \pm 17.9$ & $<0.05$ \\
\hline BDNF 72 fmol 5 min after Bicu 500 pmol & 6 & $108.75 \pm 3.41$ & $100 \pm 8.12$ & ns & $112.88 \pm 8.00$ & $100 \pm 6.81$ & ns \\
\hline BDNF 72 fmol 15 min after Bicu 500 pmol & 6 & $76.80 \pm 3.42$ & $100 \pm 5.55$ & $<0.05$ & $79.57 \pm 5.02$ & $100 \pm 3.64$ & $<0.05$ \\
\hline BDNF 72 fmol 30 min after Bicu 500 pmol & 7 & $51.63 \pm 6.32$ & $100 \pm 3.80$ & $<0.0001$ & $46.53 \pm 6.26$ & $100 \pm 5.95$ & $<0.001$ \\
\hline BDNF 72 fmol & 10 & $49.66 \pm 5.42$ & $100 \pm 4.00$ & $<0.0001$ & $49.28 \pm 5.85$ & $100 \pm 22.48$ & $<0.05$ \\
\hline
\end{tabular}

Values are means \pm SE normalized to the respective responses recorded $90 \mathrm{~s}$ before BDNF injection. GABA, $\gamma$-aminobutyric acid; Bicu, bicuculline.

Table 2) was modified. However, when coinjected with 36 fmol of BDNF, 250 pmol of bicuculline impaired the BDNF inhibitory effect on the 90-s mean number $(P>0.05, n=15$; Fig. 5A, Table 2$)$ and intensity $(P>0.05, n=15$; Fig. $5 B$,

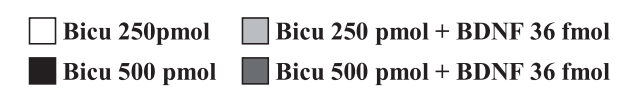

A

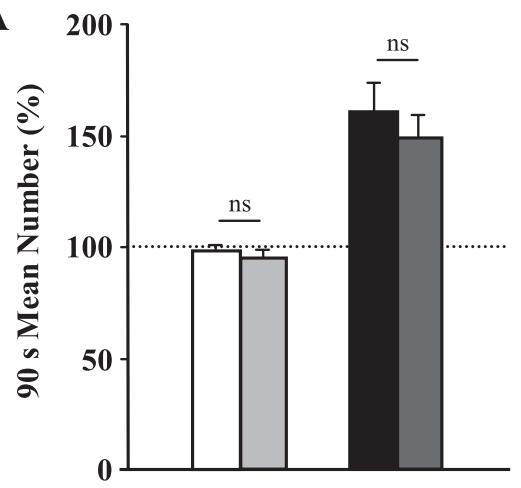

B

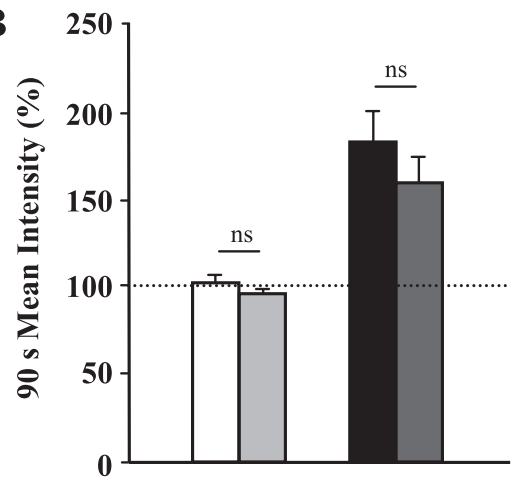

Fig. 5. BDNF inhibitory effects on rhythmic swallowing is impaired by bicuculline (Bicu). Effects of bicuculline alone ( $250 \mathrm{pmol}, n=8$; or $500 \mathrm{pmol}$, $n=11$ ) or coinjected with 36 fmol BDNF within the SwCPG on 90-s mean number $(A)$ and intensity $(B)$ of swallows triggered by SLN stimulation are shown: 250 pmol bicuculline had no effect on the mean number and intensity of swallows, while 500 pmol bicuculline induced a significant increase on the number and intensity of swallows. Moreover, bicuculline blocked BDNF inhibitory effects: neither 90 -s mean number nor intensity of swallows was reduced when BDNF was coinjected with $250 \mathrm{pmol}(n=15)$ or $500 \mathrm{pmol}(n=$ 12) bicuculline. Values are means \pm SE normalized to the respective responses recorded just before injection.
Table 2) of swallows. As previously shown (43), bicuculline induced a potentiation of swallowing. Indeed, an injection of 500 pmol of bicuculline resulted in an increase in the 90-s mean number $(60 \%, P<0.01, n=11$; Fig. $5 A$, Table 2$)$ and intensity ( $84 \%, P<0.01, n=11$; Fig. $5 B$ and Table 2$)$ of swallows, revealing a tonic GABAergic inhibition. Interestingly, when coinjected with $36 \mathrm{fmol}$ of BDNF, this facilitatory effect of $500 \mathrm{pmol}$ of bicuculline was not reduced $(P>0.05$; Fig. $5 B$ ): neither the 90 -s mean number nor the intensity of swallows was changed. In consequence, when coinjections of BDNF with bicuculline were compared with control sequences recorded before any injection, the number and intensity of swallows were significantly increased (Table 2).

To further investigate the blockade of BDNF inhibitory effect by bicuculline, $72 \mathrm{fmol}$ of BDNF was injected within the SwCPG $5 \min (n=6), 15 \min (n=6)$, or $30 \min (n=7)$ after microinjection of 500 pmol of bicuculline (Fig. 6 and Table 2). Five minutes after bicuculline microinjection, no inhibitory effect of BDNF on the swallowing reflex was recorded: neither the 90 -s mean number $(P>0.05$; Fig. $6 A)$ nor the intensity $(P>0.05$; Fig. $6 B)$ of swallows was significantly changed. Fifteen minutes after bicuculline microinjection, a slight but significant BDNF inhibitory effect was observed. Indeed, a decrease in the 90 -s mean number $(23 \%, P<0.05$; Fig. $6 A)$ as well as in intensity $(21 \%, P<0.05$; Fig. $6 B)$ was recorded. However, it was necessary to wait until $30 \mathrm{~min}$ after bicuculline microinjection to obtain an inhibitory effect of BDNF similar to that observed when BDNF alone was injected (number: $48 \%$ decrease, $P<0.001$, Fig. $6 A$; intensity: $53 \%$ decrease, $P<0.001$, Fig. $6 B$ ).

Control experiment involving microinjection within the SwCPG. Control experiments (trials on 4 different rats) indicated that microinjections of $0.9 \% \mathrm{NaCl}$ within the SwCPG affected neither the 90 -s mean number $(100 \pm 4.01 \%$ before injection vs. $103.23 \pm 4.96 \%$ after $\mathrm{NaCl}$ injection, $P>0.05$; data not shown) nor the 90 -s mean intensity $(100 \pm 2.1 \%$ before injection vs. $99.95 \pm 2.28 \%$ after $\mathrm{NaCl}$ injection, $P>0.05$; data not shown) of swallows. Moreover, in some experiments, $0.9 \% \mathrm{NaCl}$ was injected within the SwCPG at various times (3-10 $\mathrm{min})$ before the injection of BDNF (72 fmol). In all cases, the inhibitory effect of BDNF on the number and intensity of swallows was unaltered (data not shown). 


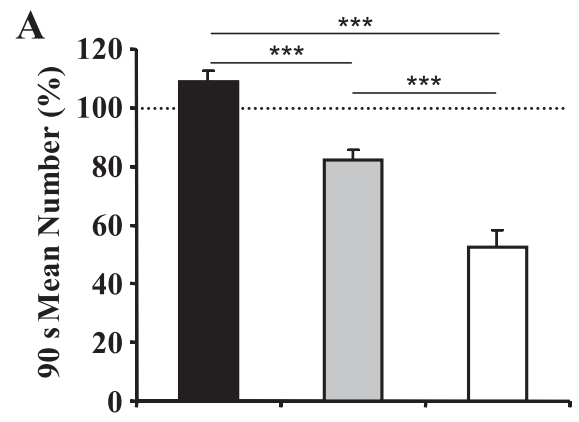

B

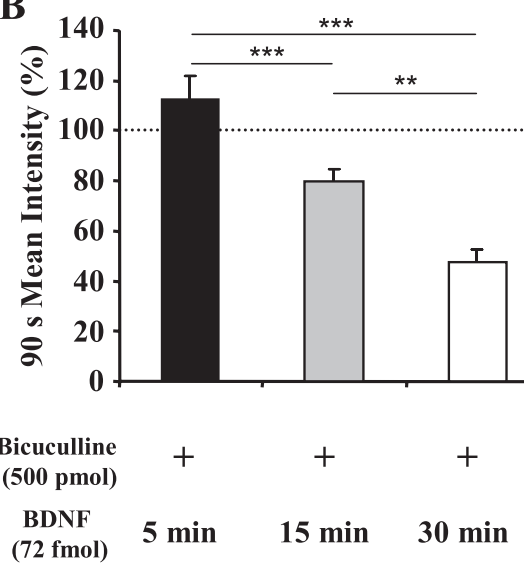

Fig. 6. Bicuculline blockade of BDNF inhibitory effects on swallowing was reversible. BDNF microinjections were performed $5(n=6), 15(n=6)$, or 30 $(n=7)$ min after 500 pmol bicuculline. BDNF injected 5 min after bicuculline had no significant effect on swallowing. When BDNF was injected $15 \mathrm{~min}$ later, the $90 \mathrm{~s}$ mean number $(A)$ and intensity $(B)$ of swallows were significantly lowered. After $30 \mathrm{~min}, \mathrm{BDNF}$ inhibitory effects were greater: number $(A)$ and intensity $(B)$ of swallows triggered by SLN stimulation were significantly reduced. Values are means $\pm \mathrm{SE}$ normalized to the respective responses recorded just before injection. $* * P<0.001, * * * P<0.0001$.

SLN stimulation increased endogenous BDNF content within the DVC. In addition, we investigated whether endogenous BDNF levels could be modified by the stimulation of laryngeal afferent fibers. With the same SLN stimulation paradigm as that used to study swallowing (i.e., $5 \mathrm{~s}$ each $30 \mathrm{~s}$ ) for $2 \mathrm{~h}$, our results showed a significant decrease in BDNF protein content in the DVC $(100 \pm 6.47 \%$ for control vs. $79.84 \pm$ $3.66 \%$ for stimulated animals, $P<0.05$ ). In contrast, no significant change in BDNF protein content was recorded $(100 \pm 3.88 \%$ for control vs. $111.11 \pm 6.94 \%$ for stimulated animals, $P>0.05$ ) at the hypothalamic level (Fig. 7).

\section{DISCUSSION}

The present study provides the first evidence that in the adult rat BDNF injection within the SwCPG inhibits the swallowing reflex, a fundamental motor component of food intake. In addition, our results show that the inhibitory effect of BDNF implies TrkB activation. Our data suggest that this inhibitory action is likely mediated through a GABAergic signaling system. Finally, using the same stimulation paradigm as that used to induce rhythmic swallowing, we demonstrated that the endogenous BDNF protein content within the DVC was decreased by stimulation of laryngeal afferent fibers.

Methodological considerations. While triggering swallowing by a physiological stimulus such as slight touch, pressure, or water application in the oropharyngeal area would best reproduce physiological conditions, this approach was not appropriate to obtain reproducible data in anesthetized animals. Thus, since it is well established that stimulation of the SLN induces swallows identical to those elicited by other types of oropharyngeal stimulation $(7,9,19)$, we used electrical stimulation of the SLN to trigger rhythmic swallowing in the anesthetized animal. Although in physiological conditions of ingestion rats generally present individual swallows concomitant with a brief inhibition of respiratory activity, it should be noted that rhythmic swallowing with prolonged inhibition of breathing is also observed when rats ingest liquid diet or drink a large amount of liquid.

BDNF-TrkB signaling inhibited swallowing. BDNF microinjections within the SwCPG resulted in a transient inhibition of the rhythmic swallowing induced by repetitive SLN stimulation. This inhibitory effect appeared to be specific, since 1) swallowing inhibition was never observed with $0.9 \% \mathrm{NaCl}$ alone (present study; see also Ref. 9) and 2) the BDNF effect was dose dependent, with $7.2 \mathrm{fmol}$ as a subthreshold dose under our experimental conditions. Moreover, while the DVC is also an integrative center for autonomic cardiac and respiratory functions, the highest BDNF dose affecting swallowing had no effect on heart rate and respiratory frequency, confirming the role of BDNF as specific to ingestive functions rather than other autonomic functions, at the level of the SwCPG.

The specificity of BDNF effects was confirmed by the absence of inhibition of swallowing by this neurotrophin when coinjected with K-252a, a permeant membrane antagonist of TrkB receptors $(24,38)$. BDNF binds to two structurally unrelated plasma membrane receptor types, the low-affinity p75 neurotrophin receptor and the high-affinity TrkB receptor that contains an intracellular tyrosine kinase catalytic domain $(31,39)$. Both receptors can act independently but also interact with each other (5). Interestingly, it has been shown that TrkB receptors are highly expressed within the DVC, not only on the afferent fibers but also on the efferent pathway, since neurons of the DMNX are also TrkB positive (45). Our results strongly suggest that BDNF inhibition of swallowing is specifically mediated by TrkB receptor signaling.

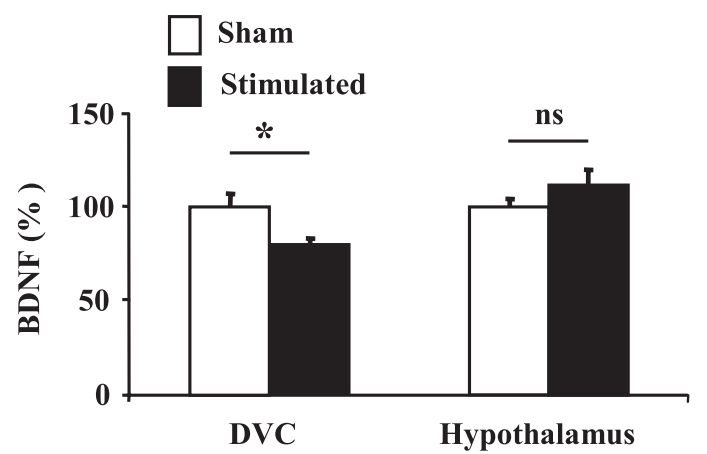

Fig. 7. Comparison of endogenous BDNF protein content within the dorsal vagal complex (DVC) and hypothalamus. After long trains of SLN stimulation $(1.5 \mathrm{~V}, 0.2 \mathrm{~ms}, 30 \mathrm{~Hz}, 5 \mathrm{~s}$ every $30 \mathrm{~s}$ for $2 \mathrm{~h} ; n=5)$ a significant decrease in BDNF protein content was measured within the DVC but not within the hypothalamus of the same rats. Each column represents mean relative BDNF protein content measured after $2 \mathrm{~h}$ of rhythmic swallowing induced by SLN stimulation compared with sham treatment control group $(n=5)$. Values are means $\pm \mathrm{SE}$ normalized to the respective sham treatment control values. $* P<0.05$. 
BDNF interacted with GABAergic signaling to inhibit swallowing. The SwCPG is located in the NTS, which is particularly rich in GABAergic interneurons (18). Moreover, GABA has been shown to act as an inhibitory mediator in swallowing $(15,43)$. In a previous study, we showed (9) that a microinjection of GABA within the NTS induces a rapid, transient, and dose-dependent inhibition of rhythmic swallowing. Conversely, we show here that bicuculline microinjection within the SwCPG induces a significant increase in the number and intensity of swallows. Such a facilitating effect of bicuculline on swallowing has been reported previously: bicuculline application into the fourth ventricle and microinjection into NTS induce long-lasting facilitation of swallowing $(6,43)$. These data suggest that GABAergic signaling plays a major role in swallowing as it exerts a tonic inhibition on this motor component of food intake. Since GABA-induced inhibitory effects (9) presented properties similar to those obtained in the present study after exogenous BDNF microinjection within the SwCPG, we tested the interaction between BDNF and GABA. IWe show here that coinjection of BDNF and GABA in the SwCPG at subthreshold doses induces a significant inhibition of swallowing. This result indicates that a synergistic interaction between BDNF and GABA inhibits swallowing. Therefore, the BDNF inhibition of swallowing may involve GABAergic signaling modulation, although BDNF and GABA effects on SwCPG neurons may involve two separate pathways. Since we showed that BDNF inhibitory effects were impaired when $\mathrm{GABA}_{\mathrm{A}}$ receptors were blocked by bicuculline, our results support the hypothesis that GABAergic neurotransmission is an important downstream effector through which BDNF inhibits swallowing.

The potentiation of GABAergic signaling by BDNF has already been reported. This potentiation could result from a presynaptic effect of BDNF inducing an increase in GABA release, a postsynaptic effect of BDNF inducing an increased expression of $\mathrm{GABA}_{\mathrm{A}}$ receptors at the cell surface, or some modifications of their properties. Thus, in the isolated dorsal horn (33) or in preparations of mammalian nerve terminals (20), BDNF facilitates the release of GABA, which in turn causes inhibition of transmission. However, in hippocampal CA1 pyramidal neurons, BDNF rapidly and reversibly potentiates postsynaptic $\mathrm{GABA}_{\mathrm{A}}$ receptor-mediated currents. In the presence of $\mathrm{BDNF}$, this $\mathrm{GABA}_{\mathrm{A}}$ response is potentiated through the activation of postsynaptic TrkB receptor (28). Moreover, in the rat visual cortex, BDNF induces a rapid increase in the total number of cell surface functional receptors (29). In the swallowing context, our results do not allow us to elucidate whether BDNF inhibitory effects are mediated by an increase in GABAergic secretion by interneurons or by an increased GABA receptivity on SwCPG neurons. Further studies at cell level would be required for a detailed breakdown of the mechanism of this interaction. Nevertheless, we have demonstrated the ability of BDNF to act as a fast modulator of synaptic activity in the SwCPG, inducing a potentiation of the GABAergic system that in turn results in an inhibition of swallowing.

SLN stimulation induced a decrease in BDNF protein content within the DVC. To further examine the involvement of BDNF in swallowing, we evaluated the effect of SLN stimulation on BDNF protein content within the DVC. For the present experiment we applied the same SLN stimulation paradigm as that used to study swallowing, i.e., $5 \mathrm{~s}$ of efficient SLN stimulation every $30 \mathrm{~s}$. As a consequence, during the 2-h experiment, the SLN was effectively stimulated only for 20 min, and in an intermittent manner. In adult rats, the meal lasts $\sim 15-20$ min (46) Moreover, a previous study showed that, in physiological conditions, the laryngeal mechanoreceptor afferent fibers of the SLN discharge at frequencies between 10 and $20 \mathrm{~Hz}(17,27)$, which is of the same order as the frequency used in our stimulation paradigm. Thus the 20-min effective stimulation used in the present experiment might be compared with afferent activities triggered during a meal.

Our results showed that a 2-h intermittent SLN stimulation induced a decrease in endogenous BDNF protein content within the DVC, while the hypothalamus content was not affected. Although the swallowing reflex does not involve the hypothalamus, this structure was taken as a reference for the central nervous regulation of feeding. Moreover, BDNF also being expressed in the hypothalamus, the content of both structures could be compared. It should be noted that SLN intermittent stimulation induced repetitive swallowing with a concomitant blockade of respiratory activity. Thus the BDNF protein content decrease observed after SLN stimulation could be the result of the swallowing induced by SLN stimulation, the apnea obtained during SLN stimulation, or both phenomena. Since we demonstrated that exogenous BDNF injection within the DVC inhibited swallowing without any modification in respiratory frequency, we favored the hypothesis that modulation of BDNF obtained is a consequence of inducing swallowing.

Another recent study in the rat reported variations in BDNF expression in both the hippocampus and the cerebral cortex after vagus nerve stimulation (10). Variations were also found under more physiological conditions. For example, it was shown that whisker stimulation results in an increase in BDNF mRNA expression in the barrel cortex of adult mice (37) and rats (30). Visual deprivation (by dark rearing) results in decreased levels of BDNF mRNA in the visual cortex, and subsequent exposure to light reestablishes normal levels (3). After hindpaw sensory restriction, BDNF mRNA relative levels increase in the rat somatosensory cortex (8). In mice, exposure to music increases the BDNF level in the hypothalamus (1). Thus the regulation of this neurotrophin expression is dependent on sensory activation. Our findings strongly suggest that BDNF modulations in the DVC may also be induced by physiological processes during which the SLN is highly activated, for example, when food travels from the mouth to the gut.

BDNF protein and mRNA, as well as TrkB protein and mRNA, are found throughout the DVC, with very heavily labeled fibers and cells in the NTS $(4,45)$. Moreover, BDNF protein has been shown to be actively transported along the axon, both in an anterograde and a retrograde manner (for review, see Ref. 35). Thus the modulation of endogenous BDNF protein content within the DVC could be the result of 1) local modifications in neosynthesis at the DVC level or 2) modification of BDNF synthesis and/or axonal transport by neurons localized outside the DVC and sending projections to the DVC. It seems unlikely that the observed variations in BDNF content could originate from SLN or vagal afferent fibers. Indeed, there are no available data supporting the view that SLN afferent neurons express BDNF mRNA or protein, 


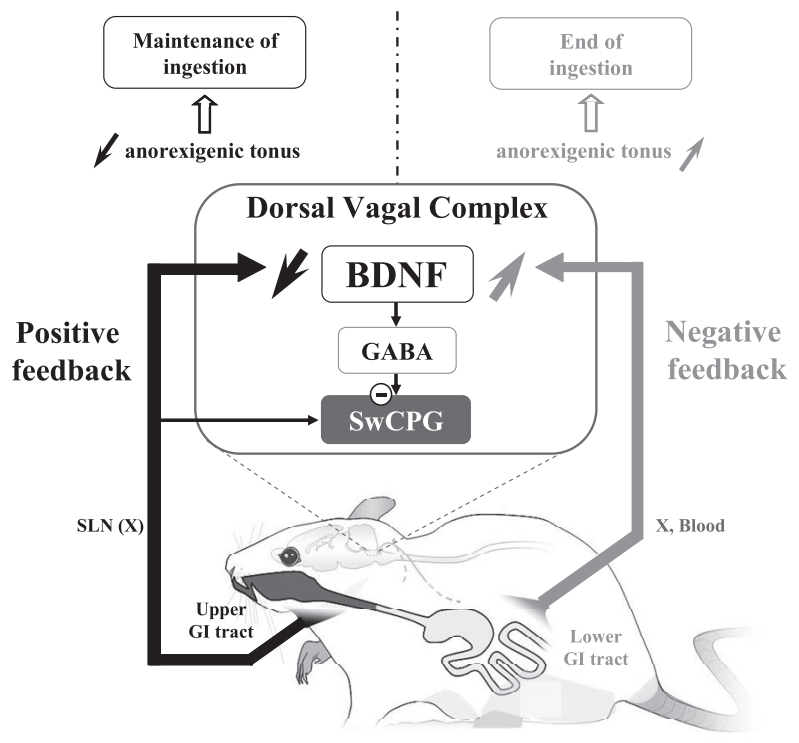

Fig. 8. Schematic view of BDNF acting in the DVC as a common integrator for both positive and negative feedback controlling the ingestive sequence. GI, gastrointestinal; $\mathrm{X}$, vagus nerve. See text for more details.

and vagal afferent fibers do not transport BDNF in an anterograde manner but only in a retrograde manner in adult rats (16). High quantities of BDNF are also expressed within viscera (26). Thus local neosynthesis modulation within the DVC, or BDNF transport modifications from vagal efferents or superior centers such as the hypothalamus or the parabrachial nucleus, which express $\operatorname{BDNF}(4,44)$ and send projections to the NTS (18), could be involved in the modulation of BDNF protein content observed at the DVC level.

\section{Perspectives and Significance}

The major finding of our study is that BDNF-TrkB signaling inhibits swallowing via a $\mathrm{GABA}_{\mathrm{A}}$-dependent mechanism in the adult rat. Previously we demonstrated (2) that BDNF is an anorexigenic factor within the DVC of the adult rat. However, the targets of anorexigenic (or orexigenic) effects are not often clearly identified. Here, the results strongly suggest that swallowing inhibition can represent one of the outputs by which BDNF alters the ingestive pattern (Fig. 8). In addition to the inhibition of swallowing by BDNF, in the present study we also show that BDNF protein content within the DVC decreases after SLN stimulation. These results can be transferred to the larger physiological context of feeding control. The eating sequence involves both positive and negative feedback. The oromotor events related to mastication and swallowing stimulate mechanoreceptors located in the upper gastrointestinal tract, thereby providing a positive feedback that allows eating to continue (25). Conversely, negative feedback is provided by the integration of signals related to satiety, such as CCK, that are emitted when the ingested food enters the lower gastrointestinal tract and allow the eating sequence to stop. We previously showed (2) that BDNF protein content decreases after a 48-h fast and increases after refeeding or after CCK or leptin treatment. All these data suggest that BDNF could exert an anorexigenic tonus within the DVC, where an increase in BDNF protein content could be a molecular basis of the integration of negative feedback induced by satiety signals.
Thus the decrease in BDNF protein content observed after SLN stimulation might result in a decrease in this anorexigenic tonus, allowing the maintenance of the eating sequence. In such a hypothesis, laryngeal afferent fiber activation could be identified as a positive feedback for the eating sequence. Interestingly, it has been suggested that the hyperphagia of $\mathrm{BDNF}+/$ - obese mice implicates an enhancement of positive feedback activated by the sensory receptors that supply oropharyngeal structures (11). Conversely, an increase in BDNF protein content depending on lower gastrointestinal signals could explain the swallowing disfacilitation observed at the end of the meal in decerebrate rats although food is still present in the mouth (12-14). Finally, BDNF could be considered as a common integrator for both positive and negative feedback controlling food intake behavior at the DVC level (Fig. 8).

\section{ACKNOWLEDGMENTS}

The authors thank Jérôme Espejo for taking care of the animals, Patrick Sanchez for software programming and for his constructive criticism in data analysis, and Marjorie Sweetho for revising the English.

\section{GRANTS}

This work was supported by funds from the Centre National de la Recherche Scientifique (CNRS), Institut National de la Recherche Agronomique (INRA), the Université Paul Cézanne Aix-Marseille III, the Conseil Général 13, and the Région Provence-Alpes-Côte d'Azur. B. Bariohay was initially supported by a doctoral fellowship from the Ministère de l'Education Nationale, de la Recherche et de la Technologie.

\section{REFERENCES}

1. Angelucci F, Ricci E, Padua L, Sabino A, Tonali PA. Music exposure differentially alters the levels of brain-derived neurotrophic factor and nerve growth factor in the mouse hypothalamus. Neurosci Lett 429: 152-155, 2007.

2. Bariohay B, Lebrun B, Moyse E, Jean A. Brain-derived neurotrophic factor plays a role as an anorexigenic factor in the dorsal vagal complex. Endocrinology 146: 5612-5620, 2005.

3. Castrén E, Zafra F, Thoenen H, Lindholm D. Light regulates expression of brain-derived neurotrophic factor mRNA in rat visual cortex. Proc Natl Acad Sci USA 89: 9444-9448, 1992.

4. Conner JM, Lauterborn JC, Yan Q, Gall CM, Varon S. Distribution of brain-derived neurotrophic factor (BDNF) protein and mRNA in the normal adult rat CNS: evidence for anterograde axonal transport. $\mathrm{J} \mathrm{Neu}$ rosci 17: 2295-2313, 1997.

5. Dechant G, Barde YA. The neurotrophin receptor $\mathrm{p} 75^{\mathrm{NTR}}$ : novel functions and implications for diseases of the nervous system. Nat Neurosci 5: 1131-1136, 2002.

6. Dong H, Loomis CW, Bieger D. Distal and deglutitive inhibition in the rat esophagus: role of inhibitory neurotransmission in the nucleus tractus solitarii. Gastroenterology 118: 328-336, 2000.

7. Doty RW. Neural organization of deglutition. In: Handbook of Physiology. Alimentary Canal. Motility. Bethesda, MD: Am. Physiol. Soc., 1968, sect. 6, vol. IV, p. 1861-1902.

8. Dupont E, Canu MH, Stevens L, Falempin M. Effects of a 14-day period of hindpaw sensory restriction on mRNA and protein levels of NGF and BDNF in the hindpaw primary somatosensory cortex. Mol Brain Res 133: 78-86, 2005.

9. Félix B, Jean A, Roman C. Leptin inhibits swallowing in rats. Am J Physiol Regul Integr Comp Physiol 291: R657-R663, 2006.

10. Follesa P, Biggio F, Gorini G, Caria S, Talani G, Dazzi L, Puligheddu M, Marrosu F, Biggio G. Vagus nerve stimulation increases norepinephrine concentration and the gene expression of BDNF and bFGF in the rat brain. Brain Res 1179: 28-34, 2007.

11. Fox EA, Byerly MS. A mechanism underlying mature-onset obesity: evidence from the hyperphagic phenotype of brain-derived neurotrophic factor mutants. Am J Physiol Regul Integr Comp Physiol 286: R994R1004, 2004.

12. Grill HJ, Kaplan JM. Sham feeding in intact and decerebrate rats. Am J Physiol Regul Integr Comp Physiol 262: R1070-R1074, 1992. 
13. Grill HJ, Kaplan JM. The neuroanatomical axis for control of energy balance. Front Neuroendocrinol 23: 2-40, 2002.

14. Grill HJ, Norgren R. Chronically decerebrate rats demonstrate satiation but not bait shyness. Science 201: 267-269, 1978.

15. Harada H, Takakusaki K, Kita S, Matsuda M, Nonaka S, Sakamoto T. Effects of injecting GABAergic agents into the medullary reticular formation upon swallowing induced by the superior laryngeal nerve stimulation in decerebrate cats. Neurosci Res 51: 395-404, 2005.

16. Helke CJ, Adryan KM, Fedorowicz J, Zhuo H, Park JS, Curtis R, Radley HE, Distefano PS. Axonal transport of neurotrophins by visceral afferent and efferent neurons of the vagus nerve of the rat. J Comp Neurol 393: 102-117, 1998

17. Hwang JC, St John WM, Bartlett D Jr. Receptors responding to changes in upper airway pressure. Respir Physiol 55: 355-366, 1984.

18. Jean A. The nucleus tractus solitarius: neuroanatomic, neurochemical and functional aspects. Arch Int Physiol Biochim Biophys 99: A3-A52, 1991.

19. Jean A. Brain stem control of swallowing: neural network and cellular mechanisms. Physiol Rev 81: 929-969, 2001.

20. Jovanovic JN, Czernik AJ, Fienberg AA, Greengard P, Sihra TS. Synapsins as mediators of BDNF-enhanced neurotransmitter release. Nat Neurosci 3: 323-329, 2000.

21. Kernie SG, Liebl DJ, Parada LF. BDNF regulates eating behavior and locomotor activity in mice. EMBO J 19: 1290-1300, 2000.

22. Kessler JP, Jean A. Identification of the medullary swallowing regions in the rat. Exp Brain Res 57: 256-263, 1985.

23. Kessler JP, Cherkaoui N, Catalin D, Jean A. Swallowing responses induced by microinjections of glutamate and glutamate agonists into the nucleus tractus solitarius of ketamine anaesthetized rats. Exp Brain Res 83: 151-158, 1990.

24. Knüsel B, Hefti F. K-252 compounds: modulators of neurotrophin signal transduction. J Neurochem 59: 1987-1996, 1992.

25. Lebrun B, Bariohay B, Moyse E, Jean A. Brain-derived neurotrophic factor (BDNF) and food intake regulation: a minireview. Auton Neurosci 126-127: 30-38, 2006.

26. Lommatzsch M, Braun A, Mannsfeldt A, Botchkarev VA, Botchkareva NV, Paus R, Fischer A, Lewin GR, Renz H. Abundant production of brain-derived neurotrophic factor by adult visceral epithelia Implications for paracrine and target-derived neurotrophic functions. Am J Pathol 155: 1183-1193, 1999.

27. Mifflin SW. Intensity and frequency dependence of laryngeal afferent inputs to respiratory hypoglossal motoneurons. J Appl Physiol 83: 1890_ $1899,1997$.

28. Mizoguchi $\mathbf{Y}$, Ishibashi $\mathbf{H}$, Nabekura $\mathbf{J}$. The action of BDNF on GABA $A_{A}$ currents changes from potentiating to suppressing during maturation of rat hippocampal CA1 pyramidal neurons. J Physiol 548: 703-709, 2003.

29. Mizoguchi Y, Kanematsu T, Hirata M, Nabekura J. A rapid increase in the total number of cell surface functional $\mathrm{GABA}_{\mathrm{A}}$ receptors induced by brain-derived neurotrophic factor in rat visual cortex. J Biol Chem 278: 44097-44102, 2003.

30. Nanda SA, Mack KJ. Seizures and sensory stimulation result in different patterns of brain derived neurotrophic factor protein expression in the barrel cortex and hippocampus. Mol Brain Res 78: 1-14, 2000.
31. Patapoutian A, Reichardt LF. Trk receptors: mediators of neurotrophin action. Curr Opin Neurobiol 11: 272-280, 2001.

32. Pelleymounter MA, Cullen MJ, Wellman CL. Characteristics of BDNFinduced weight loss. Exp Neurol 131: 229-238, 1995.

33. Pezet S, Cunningham J, Patel J, Grist J, Gavazzi I, Lever IJ, Malcangio M. BDNF modulates sensory neuron synaptic activity by a facilitation of GABA transmission in the dorsal horn. Mol Cell Neurosci 21: 51-62, 2002.

34. Pollock GS, Vernon E, Forbes ME, Yan Q, Ma YT, Hsieh T, Robichon R, Frost DO, Johnson JE. Effects of early visual experience and diurnal rhythms on BDNF mRNA and protein levels in the visual system, hippocampus, and cerebellum. J Neurosci 21: 3923-3931, 2001.

35. Poo MM. Neurotrophins as synaptic modulators. Nat Rev Neurosci 2: 24-32, 2001.

36. Rios M, Fan G, Fekete C, Kelly J, Bates B, Kuehn R, Lechan RM, Jaenisch R. Conditional deletion of brain-derived neurotrophic factor in the postnatal brain leads to obesity and hyperactivity. Mol Endocrinol 10: 1748-1757, 2001.

37. Rocamora N, Welker E, Pascual M, Soriano E. Upregulation of BDNF mRNA expression in the barrel cortex of adult mice after sensory stimulation. J Neurosci 16: 4411-4419, 1996.

38. Tapley P, Lamballe F, Barbacid M. K252a is a selective inhibitor of the tyrosine protein kinase activity of the trk family of oncogenes and neurotrophin receptors. Oncogene 7: 371-381, 1992

39. Thoenen H. Neurotrophins and neuronal plasticity. Science 270: 593-598, 1995.

40. Wang CF, Bomberg E, Billington C, Levine A, Kotz CM. Brainderived neurotrophic factor in the hypothalamic paraventricular nucleus increases energy expenditure by elevating metabolic rate. Am J Physiol Regul Integr Comp Physiol 293: R992-R1002, 2007.

41. Wang CF, Bomberg E, Billington C, Levine A, Kotz CM. Brainderived neurotrophic factor in the hypothalamic paraventricular nucleus reduces energy intake. Am J Physiol Regul Integr Comp Physiol 293: R1003-R1012, 2007.

42. Wang CF, Bomberg E, Levine A, Billington C, Kotz CM. Brainderived neurotrophic factor in the ventromedial nucleus of the hypothalamus reduces energy intake. Am J Physiol Regul Integr Comp Physiol 293: R1037-R1045, 2007.

43. Wang YT, Bieger D. Role of solitarial GABAergic mechanisms in control of swallowing. Am J Physiol Regul Integr Comp Physiol 261: R639R646, 1991.

44. Xu B, Goulding EH, Zang K, Cepoi D, Cone RD, Jones KR, Tecott LH, Reichardt LF. Brain-derived neurotrophic factor regulates energy balance downstream of melanocortin-4 receptor. Nat Neurosci 7: 736$742,2003$.

45. Yan Q, Radeke MJ, Matheson CR, Talvenheimo J, Welcher AA, Feinstein SC. Immunocytochemical localization of TrkB in the central nervous system of the adult rat. J Comp Neurol 378: 135-157, 1997.

46. Zheng H, Patterson LM, Phifer CB, Berthoud HR. Brain stem melanocortinergic modulation of meal size and identification of hypothalamic POMC projections. Am J Physiol Regul Integr Comp Physiol 289: R247R258, 2005. 